Aim of the study: To determine reasons for the increase in caries among children/adolescents treated for neoplasms.

Material and methods: Health promoting behaviour, oral hygiene (PLI), gingiva (GI), dentition (DMFt/DMFs), number of teeth with white spot lesions (WSL), and enamel defects (ED) were assessed in three groups of $60 \mathrm{pa}$ tients each. The three groups were as follows: under chemotherapy $(\mathrm{CH})$, after chemotherapy $(\mathrm{PCH})$, and generally healthy (CG). Medical files supplied information on neoplasm type, chemotherapeutic type and dose, age at treatment start, chemotherapy duration, and complications. Statistical analysis was performed with Mann-Whitney $U$ test and Spearman's rho test. Results: The age at which chemotherapy was started/its duration was 5.9 $\pm 4.0 / 1.3 \pm 0.5$ years in $\mathrm{PCH}$ and 9.12 $\pm 4.44 / 0.8 \pm 0.3$ years in $\mathrm{CH}$; $\mathrm{PCH}$ completed treatment $4.9 \pm 3.4$ years ago. Chemotherapy most often included vincristine (VCR), etoposide (VP-16), adriamycin (ADM), cyclophosphamide (CTX), cisplatin (CDDP), and ifosphamide (IF). Mucositis occurrence was $28.33 \%$ in $\mathrm{PCH}$ and $45.00 \%$ in $\mathrm{CH}$; vomiting occurrence was $43.33 \%$ and $50.00 \%$, respectively. Nutrition and prophylaxis mistakes occurred more often in $\mathrm{CH} / \mathrm{PCH}$ than in CG; PLI, GI, caries incidence and severity, and the number of teeth with WSL were higher. Correlation between caries incidence and chemotherapeutic type and dose, age at treatment start and treatment duration, mucositis, emesis, PLI, GI, ED, no fluoride prophylaxis, and nutritional mistakes was established. Ifosphamide and mucositis treatment played a major role in chemotherapy; after chemotherapy - ED and CTX, ADM, IF, and VP-16. Conclusions: Caries in permanent teeth in children/adolescents undergoing chemotherapy result from nutritional mistakes, poor prophylaxis, and indirectly from chemotherapy complications (first mucositis and emesis, and later developmental ED).

Key words: caries, chemotherapy, mucositis, developmental ED, eating habits, oral hygiene.

Contemp Oncol (Pozn) 2016; 20 (1): 45-51 DOI: $10.5114 /$ w0.2015.55319

\section{Factors influencing caries incidence in permanent teeth in children/ adolescents under and after anti-neoplastic treatment}

\author{
Ewa Krasuska-Sławińska1, Agnieszka Brożyna ${ }^{1}$, \\ Bożenna Dembowska-Bagińska ${ }^{1}$, Dorota Olczak-Kowalczyk ${ }^{2}$
}

${ }^{1}$ The Children's Memorial Health Institute, Warsaw, Poland

${ }^{2}$ Department of Pediatric Dentistry, Warsaw Medical University, Warsaw, Poland

\section{Introduction}

The use of chemotherapeutics presents a risk of side effects. Oral chemotherapy complications might result directly from drug impact on dental and periodontal tissues, mucosa, and salivary glands, or indirectly from general complications, such as malnutrition or metabolic/neurological disorders. Mucositis, fungal infections, salivary secretion disorders, and neuropathies are examples of early oral complications, and dental developmental disorders are examples of late complications [1-15]. Caries is considered to be an early complication; however, clinical observations suggest its risk remains high even many years after chemotherapy completion [8, 14].

The study objective: assess the impact of anti-neoplastic chemotherapy on caries incidence in permanent teeth, and establish the reasons for caries increase in children/adolescents under/after chemotherapy.

\section{Material and methods}

Patients

The study included 180 patients of the Children's Memorial Hospital, divided into three groups: $\mathrm{CH}-60$ patients undergoing chemotherapy (patients of the Department of Oncology at least three months from onset of chemotherapy); $\mathrm{PCH}-60$ patients after chemotherapy (patients of the Department of Oncology at least one year after chemotherapy completion); and CG - 60 generally healthy patients (patients of the Department of Paediatric Dentistry of the Children's Memorial Hospital). Patients/their parents/ their legal guardians gave written consent. Children undergoing radiation therapy in the head and neck region or with chronic diseases other than neoplasms were excluded. The study included as many oncology patients as were available during the period 2009-2013.

\section{Methods}

The study was approved by the Children's Memorial Hospital Commission for Bioethics on May 12, 2010 (permit 95/KBE/2010). The study included retrospective analysis of medical files and physical dental examination.

Patient medical files were analysed retrospectively for information on: neoplasm type, age at treatment start, treatment duration, type and accumulated dose of administered drugs, and mucositis occurrence and severity. Mucositis severity was scored from the notes with CTCAE v4.0, as follows: I - redness; || - single ulcerations, pseudomembranes; III - clustered ulcerations, pseudomembranes, provoked bleedings; and IV - extensive tissue necrosis, spontaneous bleeding [1]. 
Medical history was obtained by talking to patients and their parents/legal guardians about eating habits (cariogenic snack intake), oral hygiene, and prevention with fluoride.

Dental examination, performed at a dental practice, assessed oral hygiene, gingiva, dentition, and potential visible decrease in salivary secretion. This was performed by physicians employed at the Department of Paediatric Dentistry of the Children's Memorial Hospital under supervision of authors of the study.

The plaque index (PLI) assessed oral hygiene, and the Silness-Löe $(2,3)$ index (GI) assessed gingival tissues. Plaque on buccal and lingual surfaces of teeth 16 (55), 12, 24 (64), 36 (75), 32, and 44 (84) were recorded (deciduous teeth were assessed only if no permanent analogical teeth were present in children with mixed dentition) as follows: 0 - no plaque; 1 - no visible plaque, only seen on probing; 2 - plaque seen with the naked eye, forming a thin layer at gingival margin; and 3 - plaque visible in the gingival crevice, abundant at gingival margin and on tooth surface. The PLI was the sum of all mean scores for all assessed surfaces.

Gingiva around teeth 16 (55), 12, 24 (64), 36 (75), 32, and 44 (84) were assessed as follows: 0 - no visible inflammation; 1 - mild inflammation and redness, no bleeding on probing; 2 - moderate inflammation, redness, oedema, glazing, and bleeding on probing; and 3 - severe inflammation, marked redness and hypertrophy, ulceration, and a tendency for spontaneous bleeding. The GI was the sum of mean scores for all assessed surfaces.

Carious lesions, fillings, teeth missing due to caries/ developmental defects - enamel opacities and hypopla- sia - were assessed. Carious lesions assessment followed ICDAS - II, where codes 1 and 2 qualified as WSL (white/ dark opacity, poorly visible on humid/dried surfaces), and codes 3 and higher qualified as carious lesions ( 3 - localised enamel breakdown within opaque/pigmented enamel with no visible dentine/underlying dentine shadow; 4 - visible dentine with/without localised enamel loss; 5 - distinct cavity with visible dentine; and 6 - extensive cavity with visible dentine) [4]. Enamel opacities and hypoplasia were scored using modified DDE-Index as follows: 0 - normal enamel; 1 - demarcated opacity; 2 - diffuse opacity; 3 - hypoplasia; 4 - other defects, combine defects; 5 - demarcated and diffuse opacities; 6 - demarcated opacity and hypoplasia; 7 - diffuse opacity and hypoplasia.

Saliva flow was assessed as follows: resting flow rate normal - drops of saliva appearing on labial mucosa within 30-60 seconds of observation; resting flow rate low - drops of saliva appearing on labial mucosa after 60 seconds of observation, and stimulated flow rate (after chewing wax) normal $>5.0 \mathrm{ml} / 5 \mathrm{~min}$; low: $3.5-5 \mathrm{ml} / 5 \mathrm{~min}$.

Caries occurrence and DMFt, the sum of carious teeth (Dt), teeth lost to caries (Mt), and filled teeth (Ft), were assessed. Teeth lost to caries were distinguished from lack of tooth germs on the basis of medical/dental history and radiological examination; moreover, all extractions due to caries were performed in the Department of Paediatric Dentistry.

\section{Statistical analysis}

The Shapiro-Wilk test was performed in all groups to assess the compatibility of numeric values distribution

Table 1. The most common neoplasms, age at treatment start/completion, treatment duration, and drugs used in respective groups

\begin{tabular}{|c|c|c|c|c|}
\hline \multirow[t]{2}{*}{ Parameters } & \multicolumn{3}{|c|}{$\mathrm{PCH}$} & \multirow[t]{2}{*}{$\mathrm{CH}$} \\
\hline & \multicolumn{3}{|c|}{ mean \pm SD } & \\
\hline Age at treatment start in years & \multicolumn{2}{|r|}{$5.9 \pm 4.0$} & \multicolumn{2}{|r|}{$9.12 \pm 4.44$} \\
\hline Treatment duration in years & \multicolumn{2}{|r|}{$1.3 \pm 0.5$} & \multicolumn{2}{|r|}{$0.8 \pm 0.3$} \\
\hline Time since treatment completion in years & \multicolumn{2}{|r|}{$4.9 \pm 3.4$} & \multicolumn{2}{|r|}{0} \\
\hline Anti-neoplastic drug & $n / \%$ & $\begin{array}{c}\text { mean dose } \pm \text { SD } \\
\left(\mathrm{mg} / \mathrm{m}^{2}\right)\end{array}$ & $n / \%$ & $\begin{array}{c}\text { mean dose } \pm \text { SD } \\
\left(\mathrm{mg} / \mathrm{m}^{2}\right)\end{array}$ \\
\hline VCR & $53 / 88$ & $10.46 \pm 8.0$ & $46 / 76.6$ & $9.2 \pm 12.16$ \\
\hline ACTD & $18 / 30$ & $3.06 \pm 8.54$ & $12 / 20$ & $2.654 \pm 4.621907$ \\
\hline CTX & $41 / 68.3$ & $5287.18 \pm 12233.51$ & $33 / 55$ & $2841.83 \pm 3821.813$ \\
\hline DTIC & $17 / 28.3$ & $1649.14 \pm 2757.64$ & $14 / 32.6$ & $906.08 \pm 2650.754$ \\
\hline MTX & $13 / 21.6$ & $3795.90 \pm 8195.43$ & $5 / 8.3$ & $3230.875 \pm 16245.27$ \\
\hline VP-16 & $39 / 65$ & $1434.58 \pm 1712.87$ & $47 / 78.3$ & $1298.083 \pm 1114.76$ \\
\hline CDDP & $26 / 43.3$ & $255.9167 \pm 402.0743$ & $40 / 66.6$ & $349.0667 \pm 363.6871$ \\
\hline IF & $25 / 41.6$ & $12511.67 \pm 21032.63$ & $38 / 63.3$ & $14187.5 \pm 18862,85$ \\
\hline CBDCA & $11 / 18.3$ & $1478.7 \pm 7148.41$ & $28 / 46.6$ & $1156.333 \pm 1482.473$ \\
\hline ADM & $40 / 66.5$ & $167.41 \pm 152.43$ & $37 / 61.6$ & $145.91 \pm 166.1281$ \\
\hline $5-\mathrm{FU}$ & $3 / 5$ & $83.333 \pm 457.954$ & $1 / 1.6$ & $53.333 \pm 409.661$ \\
\hline VBL & $8 / 13.3$ & $15.33 \pm 56.238$ & $3 / 5$ & $5.95 \pm 24.05301$ \\
\hline VM-26 & $7 / 11.6$ & $155.6667 \pm 446.7638$ & $8 / 13.3$ & $114.8333 \pm 396.5707$ \\
\hline Ara-C & $8 / 13.3$ & $1592.857 \pm 5498.391$ & $3 / 5$ & $871.6667 \pm 4533.03$ \\
\hline
\end{tabular}


with real distribution. Results were statistically analysed with the Mann-Whitney $U$ test (comparison of variables in particular groups) and Spearman's rho test to establish the impact of chemotherapy on oral health. Difference significance was at $p \leq 0.05$.

\section{Results}

Mean patient age in all groups was similar: $11.24 \pm 4.22$ years in $\mathrm{CH}, 11.81 \pm 3.87$ in $\mathrm{PCH}$, and $12.22 \pm 3.63$ in controls. Table 1 presents age at treatment start/completion, chemotherapy duration, and used drugs. Various specific treatment schedules were used, requiring individual adjustments. Most often, chemotherapy was used to treat the following: medulloblastoma (12.5\%), nephroblastoma (10.8\%), Burkitt’s lymphoma (10.8\%), neuroblastoma (8.3\%), rhabdomyosarcoma (6.6\%), Ewing's sarcoma (5.8\%), and, less often, chondrosarcoma, hepatoblastoma, glioblastoma, ependymoma, and osteosarcoma.

Mucositis during chemotherapy occurred in $38.33 \%$ of patients (I-10.0\%, II-21.7\%, III-6.6\%), including $28.33 \%$ in $\mathrm{PCH}$, and $45.00 \%$ in $\mathrm{CH}$. Vomiting occurred in $43.33 \%$ of $\mathrm{PCH}$ and in $55.00 \%$ of $\mathrm{CH}$ (Table 1 ).

All patients reported brushing their teeth with fluoride toothpaste twice a day. No child had taken/was taking endogenous fluoride supplements. Systematic professional fluoride preventive routines (2-4 times/year) were most often carried out in controls. Patients under chemotherapy presented the most cariogenic eating habits (Table 2).

No patient presented decreased salivary flow. Mean $\mathrm{PLI}$ and $\mathrm{GI}$ in $\mathrm{CH}$ and $\mathrm{PCH}$ were significantly higher than in

Table 2. Health habits, oral hygiene, gingiva, and caries severity in examined groups

\begin{tabular}{|c|c|c|c|c|c|}
\hline & $\mathrm{PCH}$ & $\mathrm{CH}$ & CG & \multicolumn{2}{|c|}{$p$} \\
\hline \multicolumn{6}{|c|}{$n / \%$} \\
\hline \multirow{2}{*}{$\begin{array}{l}\text { Fluoride prevention } \\
\text { (varnishes/gels) }\end{array}$} & $26 / 43.33$ & $18 / 30.00$ & $43 / 71.66$ & PCH vs. GK & $0.0002^{*}$ \\
\hline & & & & CH vs. GK & $0.0000^{*}$ \\
\hline \multicolumn{6}{|c|}{ Snacks with sucrose (sweets and drinks) } \\
\hline \multirow[t]{2}{*}{$>3 /$ day } & $17 / 28.3$ & $29 / 48.3$ & $16 / 26.6$ & PCH vs. GK & 0.841 \\
\hline & & & & CH vs. GK & $0.014^{*}$ \\
\hline \multirow[t]{3}{*}{ Number of snacks/day } & & mean $\pm S D$ & & & \\
\hline & $1.6 \pm 0.75$ & $1.75 \pm 0.43$ & $1.4 \pm 0.58$ & PCH vs. GK & 0.169 \\
\hline & & & & CH vs. GK & $0.011^{*}$ \\
\hline \multicolumn{6}{|c|}{ Oral and gingival hygiene and dentition } \\
\hline \multirow[t]{2}{*}{ PLI } & $1.4 \pm 0.812$ & $1.83 \pm 0.5$ & $0.771 \pm 0.771$ & PCH vs. GK & $0.011^{*}$ \\
\hline & & & & CH vs. GK & $0.01^{*}$ \\
\hline \multirow[t]{2}{*}{ Gl } & $0.48 \pm 0.722$ & $0.699 \pm 0.816$ & $0.269 \pm 0.668$ & PCH vs. GK & $0.022^{*}$ \\
\hline & & & & CH vs. GK & $0.011^{*}$ \\
\hline \multicolumn{6}{|l|}{ Enamel defects } \\
\hline \multirow[t]{2}{*}{ Opacities } & $6.316 \pm 6.10$ & $3.75 \pm 5.06$ & $1.866 \pm 2.64$ & PCH vs. GK & 0.000 \\
\hline & & & & CH vs. GK & 0.006 \\
\hline \multirow[t]{2}{*}{ Hypoplasia } & $1.516 \pm 3.61$ & $0.4 \pm 1.240$ & $0.15 \pm 0.55$ & PCH vs. GK & 0.003 \\
\hline & & & & CH vs. GK & 0.241 \\
\hline \multirow{2}{*}{$\begin{array}{l}\text { Combination of lesions } \\
\text { (opacities and hypoplasia) }\end{array}$} & $0.533 \pm 1.83$ & $0.166 \pm 0.71$ & $0.083 \pm 0.38$ & PCH vs. GK & 0.06 \\
\hline & & & & CH vs. GK & 0.477 \\
\hline \multicolumn{6}{|l|}{ Caries in permanent teeth } \\
\hline \multirow[t]{2}{*}{ Number of teeth with WSL } & $2.75 \pm 3.289$ & $2.21 \pm 1.762$ & $0.711 \pm 0.891$ & PCH vs. GK & $0.0000^{*}$ \\
\hline & & & & CH vs. GK & $0.0000^{*}$ \\
\hline \multirow[t]{2}{*}{ Dt } & $5.1 \pm 5.091$ & $5.8 \pm 5.446$ & $1.559 \pm 2.53$ & PCH vs. GK & $0.0000^{*}$ \\
\hline & & & & CH vs. GK & $0.0000^{*}$ \\
\hline \multirow[t]{2}{*}{ Mt } & $0.15 \pm 0.15$ & $0.25 \pm 0.976$ & $0.398 \pm 0.851$ & PCH vs. GK & 0.2357 \\
\hline & & & & CH vs. GK & 0.3319 \\
\hline \multirow[t]{2}{*}{$\mathrm{Ft}$} & $3.2 \pm 3.78$ & $2.75 \pm 3.667$ & $3.389 \pm 3.518$ & PCH vs. GK & 0.1652 \\
\hline & & & & CH vs. GK & $0.0187^{*}$ \\
\hline \multirow[t]{2}{*}{ DMFt } & $8.3 \pm 7.181$ & $8.78 \pm 6.952$ & $5.271 \pm 4.861$ & PCH vs. GK & $0.0551^{y}$ \\
\hline & & & & CH vs. GK & $0.0153^{*}$ \\
\hline
\end{tabular}


controls (Table 2). Developmental ED occurred in $83.3 \%$ of $\mathrm{PCH}, 80.0 \%$ of $\mathrm{CH}$, and $40.0 \%$ of controls. Mean numbers of teeth with developmental ED were highest in PCH (Table 2).

Caries occurred more often in $\mathrm{CH}(90.0 \%)$ and $\mathrm{PCH}$ (88.3\%) than in controls (66.6\%). In these groups, mean numbers of teeth with WSL and caries were statistically significantly higher. Despite visibly higher DMFts in both oncologic groups, statistical significance was only proven for $\mathrm{CH}$ (for PCH $p$ was at significance limit) (Table 2).

Spearman's rho was measured for all patients, assessing correlations between caries incidence and anti-neoplastic treatment, developmental ED, mucositis (II and III), gingivitis, and no professional preventive fluoride application (Table 3). The number of teeth with caries/WSL increased with age at treatment start, its duration, time elapsed since completion, number of cariogenic snacks, and PLI. Cyclophosphamide (CTX), adriamycin (ADM), ifosphamide (IF), etoposide (VP-16), cisplatin (CDDP), and IRI presented positive correlations with both DMFt and Dt. Vincristine (VCR), ACTD, VM-26, and IRI use also resulted in Dt increase. The number of teeth with WSL was correlated with VCR, carboplatin (CBDCA), CTX, ADM, IF, VP-16, and
CDDP. Doses of cytostatics also appeared to be crucial. An increase in doses resulted in higher caries incidence, mostly caused by an increase in Dt.

Spearman's rho assessing chemotherapy factors solely in PCH confirmed a correlation between DMFt, Dt, the number of teeth with WSL, the age at which treatment started, and the number of teeth with opacities. Dt was correlated with ADM and VP-16 treatments, and the number of teeth with WSL with the number of teeth with a combination of developmental ED (Table 4). However, mucositis and vomiting under chemotherapy were not significant. A similar analysis in $\mathrm{CH}$ revealed a correlation between DMFt and Dt, and IF use and mucositis. Mucositis was positively correlated with the number of teeth with WSL (Table 4). No correlation with developmental ED was established (Tables 3, 4).

\section{Discussion}

Many researchers state that children after chemotherapy are predisposed to caries [14, 20-22]; in Poland, 97.06\% presented caries (Olczak-Kowalczyk et al.). The Avşar et al.

Table 3. Statistically significant Spearman's rho assessing correlations between caries severity and chemotherapy, eating habits, oral hygiene, and gingiva in all patients

\begin{tabular}{|c|c|c|c|}
\hline Parameters & DMFt & Dt & Number of teeth with WSL \\
\hline Age when $\mathrm{CH}$ was started & 0.1154 & $0.2148^{*}$ & $0.2397^{\star}$ \\
\hline Treatment duration & 0.0797 & $0.1998^{*}$ & $0.2054^{\star}$ \\
\hline Time since completion & 0.0912 & $0.1952^{*}$ & $0.1800^{*}$ \\
\hline VCR/dose & $0.1421 / 0.1398$ & $0.3418^{*} / 0.2956^{*}$ & $0.2897^{*} / 0.2838^{*}$ \\
\hline CBDCA & $0.0541 / 0.0457$ & $0.1504 * / 0.1385$ & $0.1818^{*} / 0.1608^{*}$ \\
\hline ACTD & $0.0215 / 0.0239$ & $0.1727^{\star} / 0.1795^{\star}$ & $0.1076 / 0.1099$ \\
\hline CTX & $0.1982^{*} / 0.2241^{*}$ & $0.4041^{\star} / 0.3956^{*}$ & $0.2528^{*} / 0.2634^{*}$ \\
\hline ADM & $0.1687^{\star} / 0.1937^{\star}$ & $0.3905^{*} / 0.3983^{*}$ & $0.1833^{\star} / 0.2398^{\star}$ \\
\hline DTIC & $0.0810 / 0.0885$ & $0.1607^{\star} / 0.1705^{*}$ & $0.0717 / 0.0795$ \\
\hline IF & $0.2342^{*} / 0.2681^{*}$ & $0.3672^{*} / 0.3936^{*}$ & $0.2750^{\star} / 0.2924^{*}$ \\
\hline VP-16 & $0.2612^{\star} / 0.2326^{\star}$ & $0.4143^{*} / 0.3669^{*}$ & $0.2979^{\star} / 0.2758^{\star}$ \\
\hline CDDP & $0.1997^{*} / 0.1753^{*}$ & $0.2990^{*} / 0.2678^{*}$ & $0.3347^{\star} / 0.3076^{*}$ \\
\hline VBL & $0.0961 / 0.0949$ & $0.1517^{*} / 0.1511$ & $0.1210 / 0.1204$ \\
\hline VM-26 & $0.0974 / 0.0938$ & $0.2008^{*} / 0.2000^{*}$ & $0.0879 / 0.0909$ \\
\hline$|R|$ & $0.1785^{\star} / 0.1790^{\star}$ & $0.1793^{*} / 0.1789^{*}$ & $0.1288 / 0.1283$ \\
\hline Vomiting & 0.1138 & $0.2187^{*}$ & $0.1980^{*}$ \\
\hline Mucositis & 0.1061 & $0.2886^{*}$ & $0.2372^{\star}$ \\
\hline $2^{\circ}$ & $0.1591^{*}$ & $0.2554^{*}$ & $0.2508^{*}$ \\
\hline $3^{\circ}$ & 0.0894 & $0.1500^{*}$ & 0.1065 \\
\hline Cariogenic snack number & 0.0928 & $0.1764^{*}$ & $0.1804^{*}$ \\
\hline Varnish/gel & $-0.1649^{*}$ & $-0.2394^{*}$ & -0.1120 \\
\hline $\mathrm{Gl}$ & $0.2418^{*}$ & $0.3294^{*}$ & $0.2767^{*}$ \\
\hline PLI & 0.0403 & $0.1827^{*}$ & $0.2477^{\star}$ \\
\hline Number of teeth with opacities & $0.388^{*}$ & $0.383^{*}$ & $0.342^{*}$ \\
\hline Number of teeth with hypoplasia & $0.1592^{*}$ & $0.1587^{*}$ & $0.2358^{*}$ \\
\hline $\begin{array}{l}\text { Number of teeth with a combination } \\
\text { of ED }\end{array}$ & 0.1267 & 0.1203 & $0.1903^{*}$ \\
\hline
\end{tabular}

*Statistically significant difference; $p<0.05$ 
Table 4. Statistically significant Spearman's rho assessing correlations between caries severity and chemotherapy in PCH and $\mathrm{CH}$

\begin{tabular}{|c|c|c|c|}
\hline Parameters & DMFt & Dt & Number of teeth with WSL \\
\hline \multicolumn{4}{|c|}{$\mathrm{PCH}$ group } \\
\hline Age at start & $0.3987^{\star}$ & $0.2847^{*}$ & $0.3652^{*}$ \\
\hline ADM/dose & $0.1562 / 0.1965$ & $0.2579^{\star} / 0.2478$ & $0.0113 / 0.1657$ \\
\hline VP-16 & 0.2469 & $0.2452^{*}$ & 0.1073 \\
\hline Number of teeth with opacities & $0.4928^{*}$ & $0.4996^{*}$ & $0.3753^{*}$ \\
\hline $\begin{array}{l}\text { Number of teeth with lesion combination } \\
\text { (opacities and hypoplasia) }\end{array}$ & 0.2297 & 0.1869 & $0.3012^{*}$ \\
\hline \multicolumn{4}{|c|}{$\mathrm{CH}$ group } \\
\hline IF/dose & $0.2398 / 0.3060^{*}$ & $0.2120 / 0.2591^{*}$ & $0.1342 / 0.1484$ \\
\hline Mucositis & 0.1754 & $0.3862^{*}$ & 0.2484 \\
\hline 2 & $0.2808^{*}$ & $0.4169^{*}$ & $0.3072^{*}$ \\
\hline
\end{tabular}

and Ponce-Torres et al. studies encountered only $18 \%$ of caries-free children after chemotherapy [20, 24].

Researchers noted a higher caries incidence in oncological patients [19-24]. The Cubukçu et al. study presented a statistically significantly higher DMFt in children after chemotherapy $(3.9 \pm 0.7)$ than in controls $(1.8 \pm 0.1)$ [25]. The Avşar et al. study presented similar DMFt results: for children under chemotherapy $-7.756 \pm 4.9$, and for controls $-4.21 \pm 3.76$. In Poland, caries severity in children after chemotherapy was also significantly higher than in healthy children (DMFt $=2.1 \pm 0.6 \mathrm{vs}$. DMFt $=1.6 \pm 0.2)[4]$. The number of carious teeth (Dt/dt) was the highest DMFt component. In contrast, Alpaslan et al. [26] and Nasman et al. [27] did not observe any statistically significant differences in caries incidence between the group after chemotherapy and controls [26, 27].

Few researchers assessed caries incidence during/ shortly after chemotherapy completion. According to Hedge et al., mean DMFts in children after chemotherapy, examined at latest two weeks after treatment completion, were not statistically different from those in controls [28]. In the present study, caries severity was lowest in controls, and the difference between DMFt in $\mathrm{CH}$ and controls was statistically significant.

Dens et al. established teeth with fillings were the highest DMFt component [24]. According to the present observations and the Olczak-Kowalczyk et al. study, teeth with carious lesions were the highest DMFt component [14]. Some researchers believe highly severe caries in patients under chemotherapy is not a direct result of the treatment itself, but of inappropriate dental care. None of the children examined by Nemeth et al. underwent a dental check-up before starting chemotherapy, and none had professional fluoride prophylaxis [22]. The present $\mathrm{CH}$ and $\mathrm{PCH}$ groups presented more serious dental negligence than healthy children.

Many local and systemic factors, also treatment-associated, have an impact on dental health. Supplying the substrate necessary for the bacterial metabolism to function, i.e. carbohydrates, is unquestionably responsible for caries development $[29,30]$. Medical history often revealed nutritional mistakes in all groups. However, they were sta- tistically significantly most often made in $\mathrm{CH}$, probably because of the necessity to compensate higher metabolic requirements manifesting in oncological diseases, coupled with malaise and concomitant taste disorders. Hong et al. [31] and Lauritano and Petruzzi [32] also mention a higher number of cariogenic snacks eaten by children during chemotherapy compared to healthy children. Regular exogenous fluoride use is known to be an important factor in caries prevention [32-35]. Its absence results in severe caries, as confirmed by the present statistical analysis. Unfortunately, among the 180 patients, only 87 underwent professional preventive routines, and these were most often part of controls. According to Nasman et al., in 1994 no child undergoing chemotherapy underwent preventive fluoride routines [26]. On the other hand, Clarkson and Eden [36] reported 25 out of 60 examined patients under chemotherapy underwent professional preventive fluoride routines. However these studies were carried out years ago. Currently, common dental guidelines for post- and under-chemotherapy patients state that daily brushing with fluoride toothpaste should be accompanied by a regular enhanced fluoride preventive routine [39, 40].

Caries-risk under chemotherapeutics also results from disadvantageous local oral environment (altered salivary gland secretion and saliva properties, and vomiting), and also from mucositis. Patients in the present study did not present any visible decrease in salivary flow/consistency. Chemotherapy is often accompanied by vomiting, which promotes enamel demineralisation, and caries and dental tissue erosion [14, 42-44]. Although vomiting in $\mathrm{CH}$ patients was limited to when the drug was administered, there existed a correlation between its occurrence and the incidence of caries and local enamel lesions (carious spots). In the present study, mucositis also had an impact on caries incidence. Gohl et al. [42] also established a correlation between mucositis and caries and actinomycin D administration. The correlation between mucositis, poor oral hygiene, and caries was also confirmed by Cheng et al. [45].

Publications confirm the impact of mucositis on oral health [38, 46, 47]. The PLI was also correlated with the number of carious teeth. GI, as confirmed by statistical 
analysis, was also considered an important indicator of oral health and caries risk. In 2010, Dahloff et al. and Fonceca et al. confirmed a positive correlation between $\mathrm{Gl}$ and caries incidence [48, 49].

In the presented study, the average GI was two-times higher in $\mathrm{PCH}$, and three-times higher in $\mathrm{CH}$, than in controls. In $\mathrm{CH}$ this may mean that general health, related to chemotherapeutic treatment and early oral complications, had an impact. Unfortunately, a high GI and PLI, also in $\mathrm{PCH}$, reflected a poor preventive routine.

According to Nunn et al., the impact of chemotherapy on dental tissues also depends on chemotherapeutic type, dose, and treatment duration. The longer the chemotherapy, the higher the risk of caries [50]. Pajari et al. assessed caries incidence according to time elapsed since chemotherapy completion and, over a period of three years, noted an increase in DMFt/DMFs [37]. However, Cubukçu et al. did not establish any substantial differences between caries incidence in children before (DMFt $=3.1 \pm 0.6)$ and after (DMFt $=3.8 \pm 0.5$ ) chemotherapy, which they imply proves that chemotherapy does not promote caries [24]. In the present study, chemotherapy duration had an impact on the number of carious teeth, although no correlation with DMft and DMFs was established. Dt was also influenced by age at treatment start and time elapsed since treatment completion. Avşar et al., Cubukçu et al., and Olczak-Kowalczyk et al. came to similar conclusions [14, 20, 25].

There are no publications on the impact of respective chemotherapeutics on caries incidence. The analysis of the Spearman's rho coefficients established that it was related to certain treatments. Under chemotherapy, it could be related to early complications, and after chemotherapy, to odontogenesis disorders, leading to structure or dental tissue mineralisation abnormalities. Poorer enamel mineralisation increases the risk of demineralisation, and abnormally structured dentine formed under certain treatments predisposes to fast caries spread. The present assessment also revealed a positive correlation between caries incidence and enamel developmental abnormalities (opacities and hypoplasia). Many researchers consider enamel underdevelopment a crucial caries factor and a reason for its higher severity $[52,56]$.

Despite a lot of research concerning the impact of chemotherapy on caries intensity, it is still debatable whether chemotherapy itself has such a significant influence on caries, or if lack of dental care, dietary habits, and hygienic negligence are more crucial in the development of caries in patients undergoing antineoplastic treatment.

In conclusion, cariogenic diet and poor prophylaxis, especially poor oral hygiene and topical fluoride application, and, indirectly, chemotherapeutic use followed by its early complications (mucositis and emesis), and distant post-chemotherapy complications (such as enamel developmental abnormalities) can result in higher intensity of caries in permanent teeth in children/adolescents under chemotherapy.

The authors declare no conflict of interest.

\section{References}

1. Dembowska-Bagińska B, Filipek I, Olczak-Kowalczyk D. Odległe następstwa leczenia nowotworów ośrodkowego układu nerwowego u dzieci. In: Nowotwory ośrodkowego układu nerwowego u dzieci. Diagnostyka i leczenie. Perek D, Roszkowski M (eds.). Wydawnictwo Fundacja NEURONET, Warszawa 2006; 163-82.

2. Olczak-Kowalczyk D, Perek D, Daszkiewicz M, Adamowicz-Klepalska B, Dembowska-Bagińska B, Daszkiewicz P. Oral pathology in children harboring neoplastic diseases. Own experience. Nowa Stomatol 2003; 4: 175-9.

3. Lalla RV, Peterson DE, Brennen MT, Schubert MM: Oral toxity. In: The chemotherapy source book. Perry MC (eds.). Lippincott Williams \& Wilkins, Philadelphia 2008; 114-53.

4. Olczak-Kowalczyk D, Daszkiewicz M, Daszkiewicz P, Kowalczyk W, Dembowska-Bagińska B, Perek D. Dental complication in patients undergoing antineoplastic therapy considering CTCAE v3.0. Part I. Stom Współ 2007; 1: 20-7.

5. Fayle SA, Duggal MS, Williams SA. Oral problems and the dentist's role in the management of paediatric oncology patients. Dent Upadate 1992; 19: 152-9.

6. Belfield PM, Dwyer AA. Oral complication of childhood cancer and its treatment: current best practice. Eur J Cancer 2004; 40: 1035-41.

7. Olczak-Kowalczyk D, Adamowicz-Klepalska B, Kowalczyk W. Implications of various systemic diseases in the oral cavity in children and adolescents. P. 1 : Diseases of the mineralize tissures of teeth. Standardy Medyczne 2009; 6: 10-5.

8. Cordova Maciel JC, de Castrojr CG, Brunetto AL, Di Leone LP, Da Silveira HE. Oral health and dental anomalies in patients treated for leukemia in childhood and adolescence. Pediatr Blood Cancer 2009; 53: 361-5

9. Olczak-Kowalczyk D, Daszkiewicz M, Kowalczyk W, Daszkiewicz P, Bagińska-Dembowska B, Perek D. Dental complication in patients undergoing antineoplastic therapy considering CTCAE v3.0. Part II. Stom Współcz 2007; 14: 30-7.

10. Olczak-Kowalczyk D, Mielnik-Błaszczyk M, Adamowicz-Klepalska B, Perek D, Dembowska-Bagińska B. Developmental impairment of dentition as a late effect of anticancer treatment in early childhood: case reports. Por Stom 2004; 7: 30-4.

11. Maguire A, Welbury R. Long term effects of antineoplastic chemotherapy and radiotherapy on dental development. Dent Update 1996: 23: 188-94

12. Macleod RI, Welbury RR, Soames JV. Effects of cytotoxic chemotherapy on dental development. J Royal Soc Med 1987; 80: 207-9.

13. Holtta P, Alaluusua S, Saarinen-Pinkala U, Peltola J, Hovi L. Agenesis and microdontia of permanent teeth as late adverse after stem cell transplantation in young children. Cancer 2005; 103: 181-90.

14. Olczak-Kowalczyk D, Daszkiewicz M, Adamowicz-Klepalska B, Milenik-Błaszczyk M, Dembowska-Bagińska B, Perek D. The status of dentition and oral hygiene in children after anticancer treatment. Ann Acad Med Gedan 2004; 34: 237-55.

15. Łapiska J, Dąbrowska E, Stokowska W. Defensive and repair abilities of the pulp in carious process - a literature review. Nowa Stomatol 2004; 2: 83-6.

16. Yu-Jie-Liu, Guo-Pei-Zhu, Xi-Yin-Guan. Comparision of the NCl-CTCAE version 4.0 and version 3.0 in assessing chemioradiation-induced oral mucositis for localy advanced nosopharyngeal carcinoma. Oral Onkol 2012; 48: 554-9.

17. Silness J, Loe H. Periodontal disease in pregnancy. II Corelation between oral hygiene and periodontal conditio. Acta Odontol Scand 1964; 22: 121-35.

18. Green JC, Vermillion JR. The oral hygiene index: a method for classifying oral hygiene status. J Amer Dent Ass 1960; 61: 29-35.

19. International Caries Detection and Assessment System (ICDAS) Coordinating Committee (2005). Criteria Manual - International Caries Detection and Assessment System (ICDAS II). Available at: www.icdas.org.assessed 15 Nov 2008.

20. Avşar A, Elli M, Darka O, Pinarli G. Long-term of chemotherapy on caries formation, dental development, and salivary factors in childhood cancer survivors. Oral Surg Oral Med Oral Pathol Oral Radiol Endod 2007; 104: 781-9. 
21. Cubukçu CE, Güneş MA. Caries experience of leukemic children during intensive course of chemotherapy. J Clin Pediatr Dent 2007; 32: $155-8$

22. Nemeth O, Hermann P, Kivovics P, Garami M. Long-term effects of chemotherapy on dental ststus of children cancer survivors. Pediat Hematol Oncol 2001; 30: 208-15.

23. Ponce-Torres E, Ruíz-Rodríguez Mdel S, Alejo-González F, Hernández-Sierra JF, Pozos-Guillén. Manifestation in pediatric receiving chemotherapy for acute lymphoblastic leukemia. J Clinical Pediat Dent 2010; 34: 275-9.

24. Dens F, Boute P, Otten J, Vinckier F, Declerck D. Dental caries, gingival health, and oral hygiene of long term survivors of paediatric malignant diseses. Arch Dis Child 1995; 72: 129-32.

25. Cubukçu CE, Güneş MA. Dental health status in children with acute lymphoblastic leukemia and hemophilia. Data from a Hospital- Based pediatric dental unit. Balka J Stomat 2011; 15: 116-20.

26. Alpaslan G, Alpaslan C, Gögen H, Oğuz A, Cetiner S, Karadeniz C. Distarbances in oral dental structures in patients with pediatric lymphoma after chemotherapy. Oral Surg Oral Med Oral Patol Oral Radiol Endod 1999; 87: 317-21.

27. Nasman M, Bjork O, Soderhall S, Ringden O, Dahllof G. Distarbnes in the oral cavity in pediatric long-term survivors after diffent forms of antineoplastic therapy. Pediatr Dent 1994; 16: 217-23.

28. Hegde AM, Joshi S, Rai K, Shetty S. Evaluation of oral hygiene, status, salivary characteristics and dental caries experience in acute lymphoblastic leukemia. J Clin Pediatr Dent 2011; 35: 319-23.

29. Pilipczuk-Paluch K. The occurrence of dental caries in 7-year old children in an urban environment. Doctoral dissertation. UM, Poznan 2013.

30. Chapter 5. In: Zapobieganie i leczenie choroby próchnicowej u dzieci. Olczak-Kowalczyk D, Wagner L (eds.). Borgis, Warszawa 2013; 67-85.

31. Hong CH, Napeñas JJ, Hodgson BD, Stokman MA, Mathers-StaufferV, Elting LS, Spijkervet FK, Brennan MT; Dental Disease Section, Oral Care Study Group, Multi-national Association of Supportive Care in Cancer (MASCC)/International Society of Oral Oncology (ISOO). A systematic review of dental disease in patient undergoing cancer therapy. Support Care Cancer 2010; 18: 1007-21.

32. Lautirino D, Petruzzi M. Decayed, missing and filled teeth index and dental anormalies in long-term survivors leukemic children; A prospective controlled study. Med Oral Patol Cir Bucal 2012; 17: 977-80.

33. Adamowicz-Klepalska B, Buczkowska-Radlińska J, Iracki J, et al. Konsensus grupy ekspertów pod auspicjami Fundacji Promocji Zdrowia Jamy Ustnej w sprawie promocji zdrowie jamy ustnej i profilaktyki fluorkowej próchnicy zębów. Warszawa 2004.

34. Azaprazzhooh A, Main P. Fluoride vanish in the prevention of dental caries in children and adolescents: a review. J Can Dent Assoc 2008; 74: 73-9.

35. European Academy of Paediatric Dentistry. Guidelines on the use of fluoride in children: an EAPD policy document. Eur Arch Paediatr Dent 2009; 10: 129-35.

36. Clarkson JE, Eden O. Dental health in children with cancer: Arch Dis Child 1998; 78: 560-1.

37. Lopez BC, Esteve CG, Perez MG. Dental treatment consideration in the chemiotherapy patient. J Clin Exp Dent 2011; 3: 31-42.

38. Koralewska E, Konopka T. Preventive-therapeutic dental care protocol in children with leukemia. Czas Stom 2006; 59: 245-52.

39. Kennedy L, Diamond J. Assesment and management of chemotherapy of - induced mucositis in children. J Pediatr Oncol Nurs 1997; 14: 164-74.

40. Dental Health Nersion 3,0-10/08. Dental health following childhood cancer treatment. Childrens Oncology Group 2008.

41. Fayle SA, Curzon ME. Oral complication in pediatric patients. Pediatr Dent 1991; 13: 289-95.

42. Gohil TR, Mutave RJ, Dimba EA. Effects of chemotherapy on the oral health in pediatric oncology patients at the Kenyatta National Hospital. J Kenya Dent Ass 2011; 2: 184-9.

43. Buczkowska-Radlińska J, Kaczmarek W, Tyszler Ł, Mikołaczczyk E, Frączak B. Dental status in patients with eating disorders. Roczniki Pomorsk AM 2007; 53: 90-3.
44. Paszyńska E. Selected factors that cause salivary secretion and effect its composition - review of the current literature. Dental Forum 2005; 32: 86-9.

45. Cheng KKF, Molassiotis A, Chang AM. An oral care protocol intervention to prevent chemotherapy-induced oral mucositis in pediatric cancer patients: a pilot study. Eur J Oncol Nurs 2001; 9: 66-73.

46. Sonis ST. Oral complications of cancer therapy. Oncol 2002; 16, 5 : 680-95.

47. Stephen A, Fayle BDS, Curzon MEJ. Oral complication in pediatric patients. Pediatr Dent 1991; 13: 289-95.

48. Dahllof G. Nasman MI, Borgstrom A, Modeer T, Forsberg CM, Heimdahl A, Ringden O. Effect of chemotherapy of dental maturiny in children with hematological malignancies. Pediatr Dent 1989; 11: 303-6.

49. Almeida Cruz R, Fonseca MS, de Oliveira Costa F, de Sousa Resende Penido CV. Dental caries and gingivitis prevalence: risk factors analysis in institutionalized children. Arq Bras Odont 2010; 6: 10-8.

50. Nunn JH, Wulbury RR, Gordon PH, Kernahan J, Kraft AW. Dental caries and dental abnormalies in children treated by chemotherapy for malignant disease: A study in north of England. Peadiatr Dent 1991; 1: 131-5.

51. Pajari U, Ollila P, Lanning M. Incidence of dental caries in children with acute lymphoblastic leukemia is related to the therapy used. J Dent Child 1995; 9-10: 349-52.

52. Al.-Ghani BA, Hasan NM, Hassan JM. Enamel hypoplasia in patients with acute lymphoblastic leukemia. J Bagh College Debt 2005; $17:$ 53-6.

53. Golpaygani MV, Mehrdad K, Mehrdad A, Ansari G. An evaluation of the rate of dental caries among hypoplastic and normal teeth: A case control study. Res J Biolog Sci 2009; 4: 537-41.

54. Sobiech I, Sobol-Kober J, Remiszewski A, Sobiech P, BoguszewskaGutenbaum H. Enamel anormalies in permanent dentition of the deffrent groups of age from Warsaw region. Nowa Stomat 2000; 4: 13-7.

55. Rucińska K, Połeć G, Wal A, Hajduk A, Rońda E, Kokosińska M. Problem zmętnień szkliwa zębów stałych u dzieci. Nowa Stomatol 1997; 1/2: 31-3.

56. Sosnowska-Boroszko A, Gordon A, Siemińska J, et al. Enamel anormalies in permanent dentition of school children. Nowa Stomatol 2002; 3: 116-21.

\section{Address for correspondence}

\section{Ewa Krasuska-Sławińska}

The Children's Memorial Health Institute

Al. Dzieci Polskich 20

04-730 Warsaw, Poland

e-mail: e.krasuska@czd.pl

Submitted: 13.03 .2014

Accepted: 19.11 .2014 